Research Article

\title{
A Large-Scale Test Method for Mechanical Response of Pavement Structure
}

\author{
Xingye Zhou $\mathbb{D}^{1,2}$ and Xudong Wang ${ }^{1,2}$ \\ ${ }^{1}$ School of Transportation Science and Engineering, Harbin Institute of Technology, Harbin, Heilongjiang 150090, China \\ ${ }^{2}$ Key Laboratory of Road Structure and Material, Research Institute of Highway Ministry of Transport, Beijing 100088, China
}

Correspondence should be addressed to Xingye Zhou; zhouxingye1982@163.com

Received 22 July 2017; Revised 12 November 2017; Accepted 27 November 2017; Published 11 February 2018

Academic Editor: Ashkan Vaziri

Copyright (c) 2018 Xingye Zhou and Xudong Wang. This is an open access article distributed under the Creative Commons Attribution License, which permits unrestricted use, distribution, and reproduction in any medium, provided the original work is properly cited.

\begin{abstract}
A test method for mechanical response of pavement structure with the large scale model was presented in the study. The strain was tested on three large scale models of pavement structure with three typical pavement materials of cement concrete (CC), cement stabilized macadam (CSM) and asphalt concrete (AC) under the different load levels. Theoretical calculations of the strain on the top surface of CC, CSM and AC pavement models were also developed by BISAR3.0, which is a software for mechanical analysis based on elastic layered system. The research results indicate that the test method for mechanical response of pavement structure with large scale model presented in the study shows a low variability, and a good repeatability and reliability, which can be used as an effective way to study the mechanical response of pavement structure instead of full-scale test. The research results can provide some references for theoretical calculation of pavement structure and determination of pavement material parameters.
\end{abstract}

\section{Introduction}

The vehicle load and the changes of ambient temperature can cause excessive stress, strain, and displacement within the pavement structure, which further lead to the structural failure of pavement. In recent years, authentic mechanical response of pavement under different loading has always been the focus point in the research area of basic theory and design of pavement structure. At present, theoretical analysis and experimental test are the main methods to obtain the mechanical response of pavement structure. These two methods are usually used together to complement and verify each other. In comparison with the theoretical analysis, the experimental test can reflect the actual mechanical status of pavement structure. The experimental test has gradually become one of the most important methods to study the mechanical response of pavement structure [1]. Among the present researches, lots of experimental test were conducted to obtain the mechanical response of pavement structure on the accelerated loading facility, full-scale test track, and engineering test road. The representatives mainly include Australia Accelerated Loading Facility (ALF) test [2, 3],
Accelerated Pavement Testing (APT) with Heavy Vehicle Simulator (HVS) in United States [4] and South Africa [5, 6], Virttaa test field of Load and Traffic Laboratory of National Technical Research Centre (VTT) of Finland [7], National Center for Asphalt Technology (NCAT) test track [8, 9], WesTrack of Nevada [10], Accelerated Pavement Testing (APT) facility at French Institute of Science and Technology for Transport, Development and Networks (IFSTTAR) [11], Laboratoire Central Des Ponts Et Chaussees (LCPC) test track in Nantes of France [12-14], Centro de Estudios de Experimentación de Obras Públicas (CEDEX) test track in Madrid of Spain $[15,16]$, accelerated pavement testing with Texas Mobile Load Simulator (TxMLS) [17], full-scale test track of Research Institute of Highway of Ministry of Transport of China (RIOH Track) [18-20], AASHO Road Test of United States [21], MnRoad test road of Minnesota [22], permanent asphalt pavement test road in Shandong province of China [23], and test section on 6th Ring Road in Beijing of China [24]. For these test methods, the same or similar material types, structure forms, and load actions as actual pavement were adopted to simulate the real conditions. Accordingly, the test results can reflect the stress and 
strain distribution of actual pavement. Thus, the experimental test has been widely recognized as an important research method for mechanical response of pavement by the researchers. However, the full-scale accelerated load test is extremely complicated, which is generally matched with a set of expensive test and operation management system. High cost is inevitable to ensure the normal operation of the system. In addition, the test period is too long due to the load efficiency. It usually takes about several months to several years to draw conclusions from the initial test design. Thus, the full-scale accelerated load test cannot be widely used in research of mechanical response of pavement, because of limitation by high cost and long test period.

Accordingly, in order to develop a common and applicable research method to obtain authentic mechanical response of pavement under different loading, a large-scale model of pavement structure was designed and prepared. The test method of mechanical response with the larger scale model was proposed. The mechanical responses of typical pavement materials were studied on the large-scale model.

\section{Objective and Scope}

The primary objectives of this study are to develop a simple and reliable test method for mechanical response of pavement structure, which may be useful for obtaining the real mechanical response regularity of pavement under the action of vehicle load. Three large-scale models of pavement structure with cement concrete, cement-stabilized macadam, and asphalt concrete were prepared for the test. The influences of the material property and load level on the mechanical response were analyzed.

\section{Test Design}

3.1. Test Load. According to the common method used in present research [25-27], the vehicle load is simplified to a circular uniform distributed load with a radius of $\delta=7.5 \mathrm{~cm}$ in this study, which is convenient not only for mechanical analyses but also for comparison with the conclusion of other researches. The load acts on the model center statically, as shown in Figure 1. The load magnitude is denoted by $p$, which is a variable value. Three large-scale models of pavement structure were made with the cement concrete, cement-stabilized macadam, and asphalt concrete. The test temperature is $15^{\circ} \mathrm{C}$. For the research convenience, the load was acted on the large-scale model as follows.

First, to study the mechanical response of different pavement materials, the load magnitude is selected according to the stress level, which is the ratio of the test load to the strength of the material. The present researches indicate that the damage caused by the load to the material can be ignored, when the stress level is 0.2-0.4. Accordingly, the stress level was chosen as 0.3 in this research. The strengths of the cement concrete, cement-stabilized macadam, and asphalt concrete are $6.89 \mathrm{MPa}$, 5.02 MPa, and $2.33 \mathrm{MPa}$, respectively. The load magnitudes for cement concrete, cement-stabilized macadam, and asphalt concrete are determined as $p=2.1 \mathrm{MPa}, p=$ $1.5 \mathrm{MPa}$, and $p=0.7 \mathrm{MPa}$ by calculation, respectively.

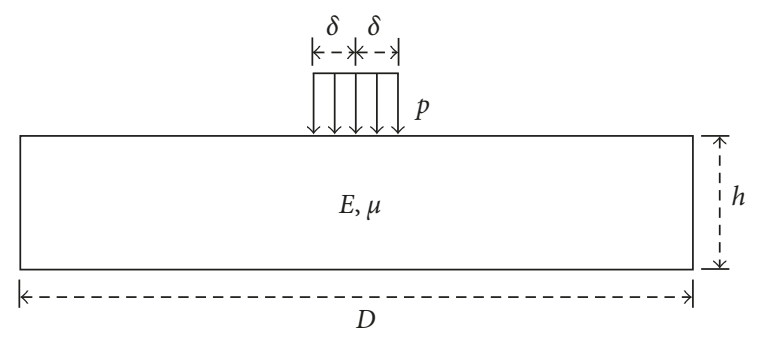

FIGURE 1: Sketch of the test model of pavement structure.

Second, to study the influence of the load level on the mechanical response, three different load magnitudes were selected for each pavement material. For the cement concrete, the load intensity $p$ is $1.3 \mathrm{MPa}, 1.7 \mathrm{MPa}$, and $2.1 \mathrm{MPa}$. For the cement-stabilized macadam, the load intensity $p$ is 1.1 MPa, 1.5 MPa, and 1.9 MPa. For the asphalt concrete, the load intensity $p$ is $0.3 \mathrm{MPa}, 0.7 \mathrm{MPa}$, and $1.1 \mathrm{MPa}$.

3.2. Model Size of Pavement Structure. The aim of this research is to find a method to simulate the pavement structure in lab between small size test and full-scale test. The more the model size is close to the actual pavement, the better the model can simulate the real situation, and the more difficult the mechanical responses of structure are tested. Thus, the model size of pavement structure was determined by considering the actual pavement structure and test difficulty.

3.2.1. Model Shape. Accordingly, the pavement structure model is designed as a cylinder. A circular uniform distributed load with the intensity of $p$ and the radius of $\delta$ is placed at the central point on the top surface of the model. The test model can be simplified to axisymmetric mechanical problem as shown in Figure 1.

3.2.2. Model Thickness. Currently in China, the thickness of asphalt surface course, single semirigid base course, and cement concrete surface course of highway are $15 \mathrm{~cm}-22 \mathrm{~cm}$, $18-20 \mathrm{~cm}$ [28], and 24-26 cm, respectively. Accordingly, the thickness of the test model shown in Figure 1 is designed as $20 \mathrm{~cm}$ to better simulate the actual pavement structure.

3.2.3. Model Diameter. In order to obtain the optimal diameter of the model, the pavement mechanical calculation software BISAR3.0 was adopted to calculate the stress and strain of the cylindrical pavement structure model under the load action. As the model can be simplified as axisymmetric mechanical problem, the $1 / 4$ model was used for calculation in the research. The load intensity $(p)$ is $2.1 \mathrm{MPa}$. The load radius $(\delta)$ is $7.5 \mathrm{~cm}$. The cement concrete is selected as an example with the modulus of $E=30,000 \mathrm{MPa}$ and Poisson's ratio of $\mu=0.18$. The diameter of the model $(D)$ is $200 \mathrm{~cm}$. The output parameters are the radial stress and strain along the diameter direction $\left(\sigma_{r}, \varepsilon_{r}\right)$ and circumferential stress and strain which are perpendicular to the diameter direction $\left(\sigma_{\theta}\right.$, $\left.\varepsilon_{\theta}\right)$. The calculation results are shown in Figures 2 and 3, 


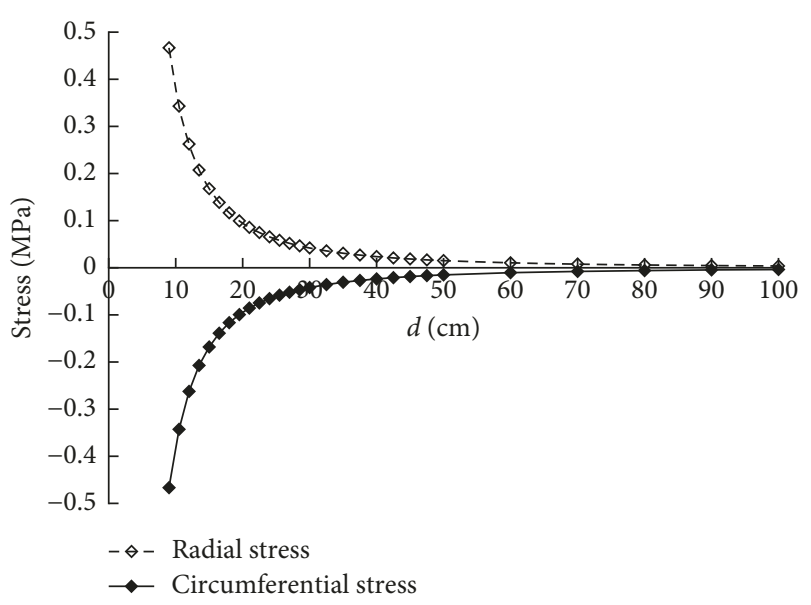

Figure 2: Calculation results of surface stress of the CC pavement structure model.

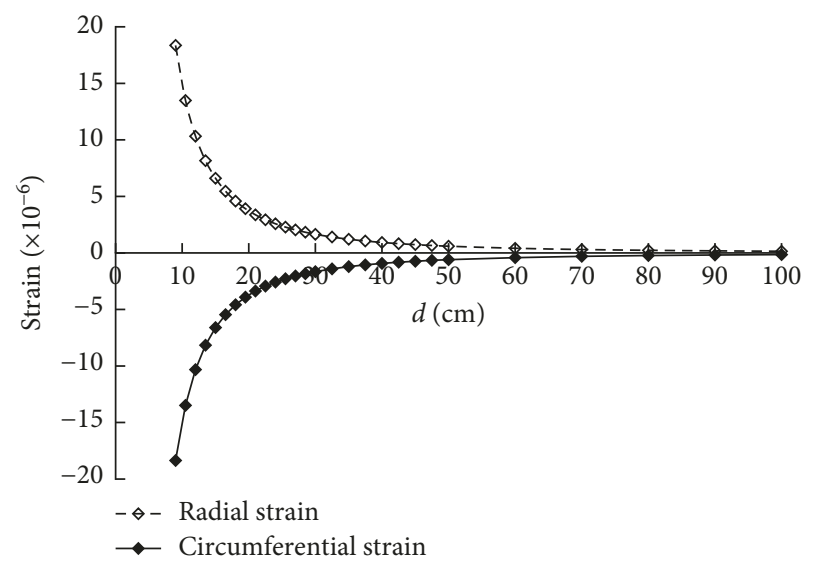

FIGURE 3: Calculation results of surface strain of the CC pavement structure model.

which indicate that the radial stress and circumferential stress of the model decrease rapidly with the increase of the distance $(d)$ from the calculation point to the load center point. When $d=30 \mathrm{~cm}$, the radial stress and circumferential stress have decreased to below $0.05 \mathrm{MPa}$; when $d=50 \mathrm{~cm}$, the radial stress and circumferential strain have been reduced to below $0.5\left({ }^{*} 10^{-6}\right)$; when $d>50 \mathrm{~cm}$, stress and strain values are too small to be considered in mechanical analysis of pavement structure. Therefore, in order to balance the accuracy to simulate the actual situation of pavement and convenience of laboratory test, the model diameter $D$ is selected as $100 \mathrm{~cm}$ finally.

3.3. Materials and Mix Proportions. The cement used for the cement concrete and cement-stabilized macadam is Ordinary Type I/II Portland.

The mix proportion of cement concrete is presented in Table 1. Naphthalene sulfonate is used as the water-reducing agent. Nature sand with the fineness modulus of 2.36 is used as the fine aggregate for cement concrete. The composition of coarse aggregate is listed in Table 2. The compressive
TABLE 1: Mix proportion of cement concrete $\left(\mathrm{kg} / \mathrm{m}^{3}\right)$.

\begin{tabular}{lcccc}
\hline Cement & $\begin{array}{c}\text { Fine } \\
\text { aggregate }\end{array}$ & $\begin{array}{c}\text { Coarse } \\
\text { aggregate }\end{array}$ & Water & $\begin{array}{c}\text { Water-reducing } \\
\text { agent }\end{array}$ \\
\hline 389 & 670 & 1243 & 148 & 5.45 \\
\hline
\end{tabular}

TABLE 2: Composition of coarse aggregate for cement concrete.

\begin{tabular}{lccc}
\hline Aggregate size $(\mathrm{mm})$ & $20-30$ & $10-20$ & $5-10$ \\
\hline Proportion $(\%)$ & 38 & 54 & 8 \\
\hline
\end{tabular}

TABle 3: Composition of macadam for cement-stabilized macadam.

\begin{tabular}{lcccccc}
\hline Aggregate size $(\mathrm{mm})$ & $20-25$ & $15-20$ & $10-15$ & $5-10$ & $3-5$ & $0-3$ \\
\hline Proportion (\%) & 16.2 & 14.8 & 11.1 & 17.9 & 11.8 & 28.2 \\
\hline
\end{tabular}

TABle 4: Aggregate composition of asphalt mixture.

\begin{tabular}{lccccccc}
\hline $\begin{array}{l}\text { Aggregate } \\
\text { size }(\mathrm{mm})\end{array}$ & $20-25$ & $15-20$ & $10-15$ & $5-10$ & $3-5$ & $0-3$ & $\begin{array}{c}\text { Mineral } \\
\text { powder }\end{array}$ \\
\hline Proportion (\%) & 19.8 & 17.6 & 12.8 & 19.8 & 7.5 & 18.5 & 4.0 \\
\hline
\end{tabular}

strength and the flexural strength are $44.8 \mathrm{MPa}$ and 6.89 $\mathrm{MPa}$, respectively, at the curing age of 28 days.

The composition of macadam for the cement-stabilized macadam is shown in Table 3. The cement dosage is $7.5 \%$. The optimum water content is $7.2 \%$.

The penetration value of asphalt for asphalt concrete is $70(0.1 \mathrm{~mm})$. The optimum asphalt content is $4.3 \%$. The aggregate gradation of asphalt mixture is displayed in Table 4. The compressive strength of asphalt concrete is $2.33 \mathrm{MPa}$ at the temperature of $15^{\circ} \mathrm{C}$.

3.4. Test Model Preparation. For the preparation of the largescale model of pavement structure, first, the materials are mixed through the large capacity of mixing equipment in the laboratory. Second, the mixtures are placed in the special moulds, which are $100 \mathrm{~cm}$ in diameter and $20 \mathrm{~cm}$ in thickness. Finally, the compaction was executed by a vibration roller. The surface of the sample is too rough to test the strain by electrical measurement. Hence, the specimen surface needs to be polished by sander and sandpaper to get a smooth surface before the test, as shown in Figure 4.

\subsection{Test System}

3.5.1. Loading System. In this research, the gantry MTS hydraulic servo system is used as the loading device. The supporting reaction frame is employed to provide the pavement structure model with random static test load in the range of $0-250 \mathrm{kN}$, as shown in Figure 5.

3.5.2. Data Acquisition System. In this study, paper-based electrical resistance strain gauges are attached on the sample surface as shown in Figure 6. The electrical measuring method is used to obtain the strain response of the sample 


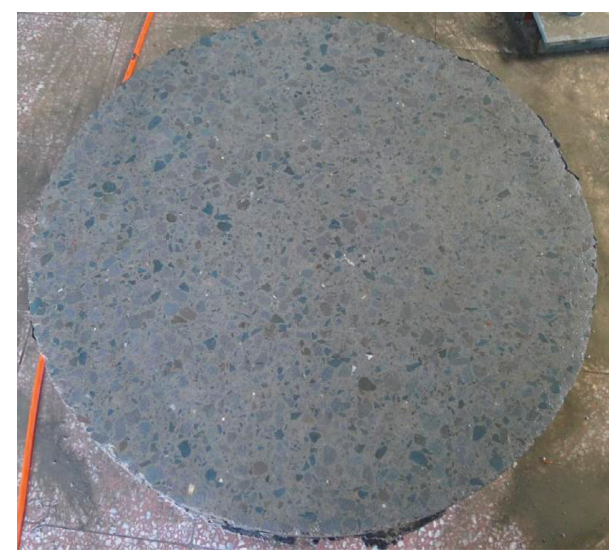

FIGURE 4: Specimen of the large-scale model of pavement structure.

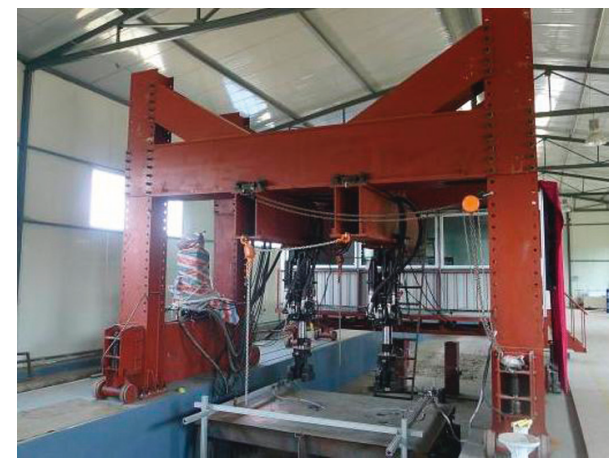

FIgURE 5: Loading system for test.

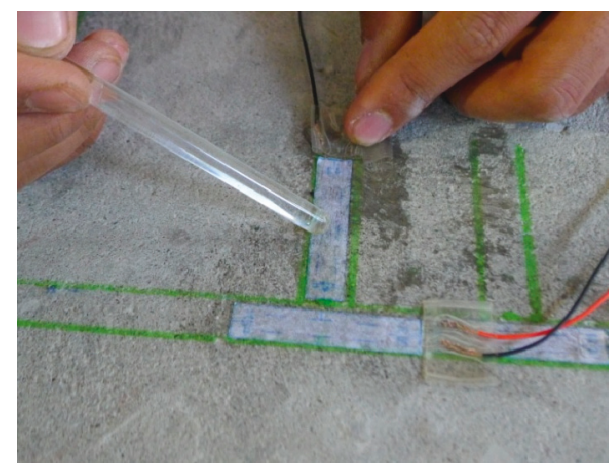

FIGURE 6: Electrical resistance strain gauge.

surface under the different loads. The accuracy of strain gauge is $0.05\left({ }^{*} 10^{-6}\right)$. The frequency of strain acquisition under the static load is $0.1 \mathrm{~Hz}$.

In consideration of the characteristic of the axisymmetric structure, radial strain along the diameter direction and circumferential strain perpendicular to the diameter direction are the main test parameters. In this research, radial strain along the diameter direction is symmetrically arranged in 8 rows and circumferential strain perpendicular to the diameter direction is symmetrically arranged in 2 rows. The strain on the symmetric point of the $1 / 4$ model was taken as average to ensure the accuracy. A certain distance is

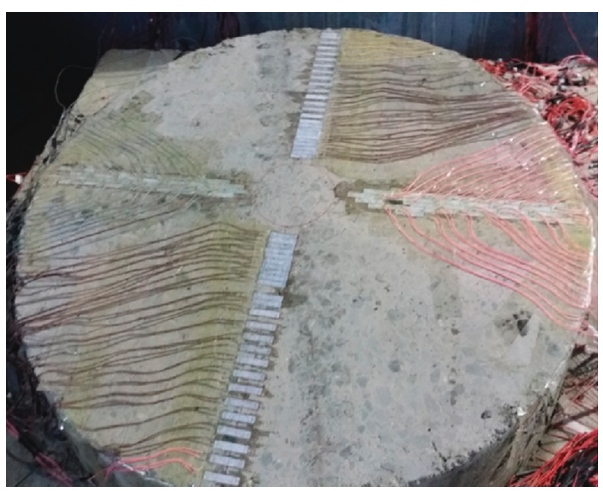

FiguRe 7: Distribution of strain gauges.

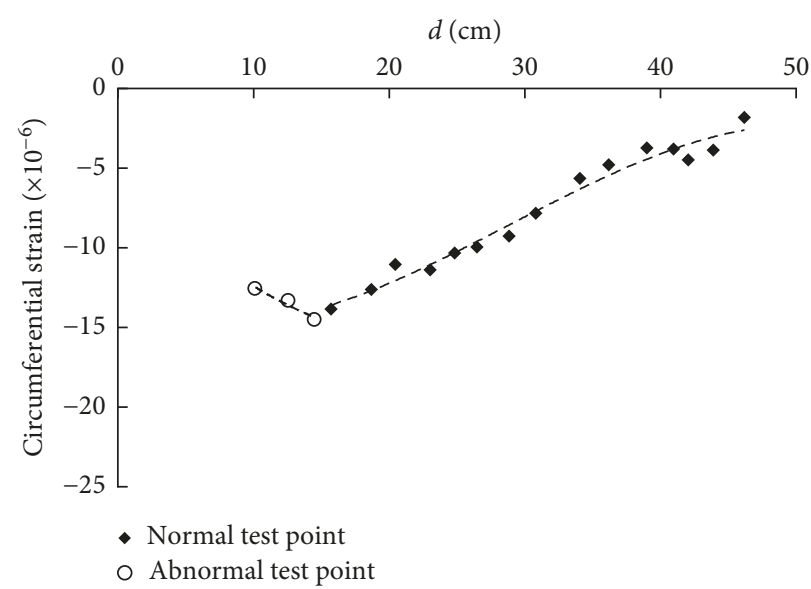

Figure 8: The test result of circumferential strain on the top of the CSM pavement structure model.

reserved between strain gauges in order to make every strain gauge work independently and has no influence on the nearby strain gauges. The distribution of strain gauges is shown in Figure 7.

\section{Test Results and Discussions}

4.1. Data Processing Method. Taking CSM pavement structure model for an example, the laws of test data and the data processing method were discussed as follows. The test results of circumferential strain on the top of the CSM pavement structure model under the static uniform load of $p=1.0 \mathrm{MPa}$ are shown in Figure 8. It can be seen that as the distance $d$ from the test point to the center point of load increases, the circumferential strain increases at first and then decreases, which is a kind of abnormal phenomenon obviously. The peak value appears at the point of $d=14 \mathrm{~cm}$. The test results indicate that the same abnormal phenomenon exists in the measured circumferential strain of CC and AC pavement structure models. Peak value usually emerges at the point of $d=12-15 \mathrm{~cm}$, as shown in Figures 9 and 10 . The load boundary effect is the main factor leading to this anomaly. Specifically, although there is no direct load acting on the model surface nearby the load, the scope near the circular load edge $(d=7.5-15 \mathrm{~cm})$ still suffers the influence of the 


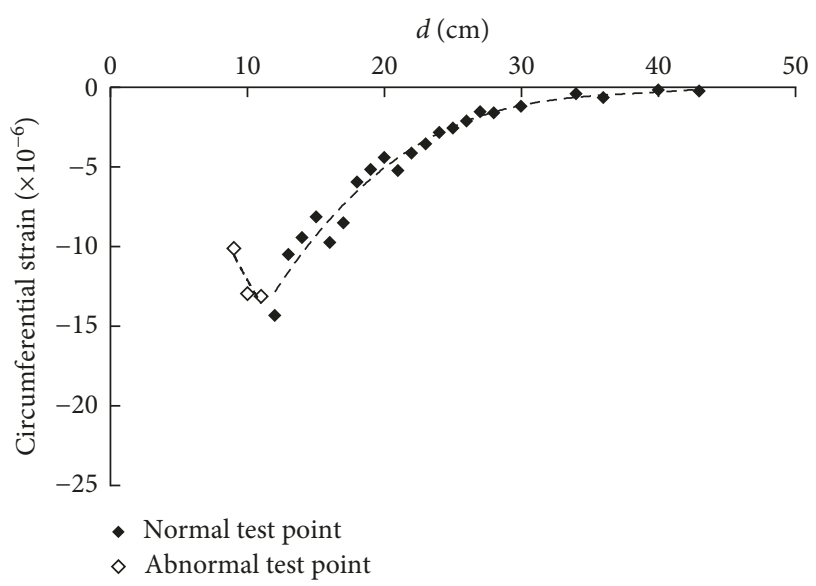

FIGURE 9: The test result of circumferential strain on the top of the CC pavement structure model.

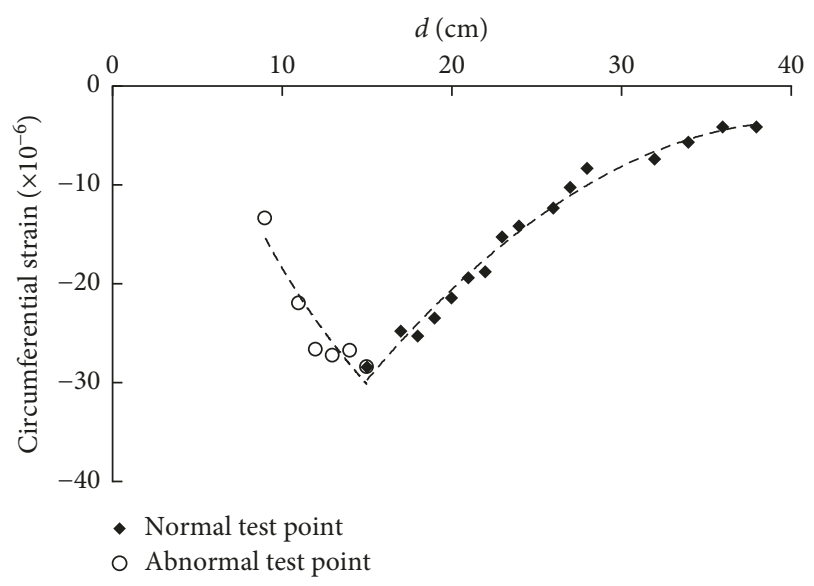

FIGURE 10: The test result of circumferential strain on the top of the AC pavement structure model.

load, which results in disorder of stress and strain on the surface of specimen. Thus, to ensure the rationality of analysis on the test results, measure points in the scope of $d=7.5-15 \mathrm{~cm}$ are removed so as to exclude the load boundary effects, as shown in Figures 11-13.

4.2. Parallel Test and Replicate Test. Due to the impacts of instrument precision, signal acquisition mode, and environmental noise on the test method, inaccuracy and distortion occurred on the measured value sometimes. To ensure the reliability of test methods, parallel test and replicate test were developed. Taking AC pavement structure model as an example, the results of parallel tests and replicate tests were discussed.

4.2.1. Parallel Test Result. In Tables 5 and 6 , the parallel test results of circumferential strain and radial strain of the AC pavement structure model are listed, respectively. As shown, the differences between the results of the 4 sets of parallel tests are very small for both circumferential strain and radial strain. The average variation coefficients are $2.1 \%$ and $2.3 \%$,

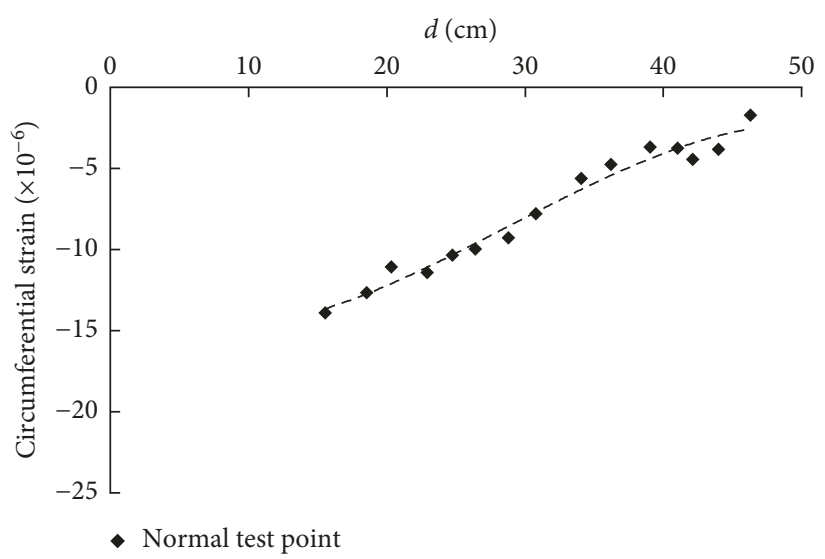

FIgURE 11: Top surface circumferential strain of the CSM model after removing the abnormal points.

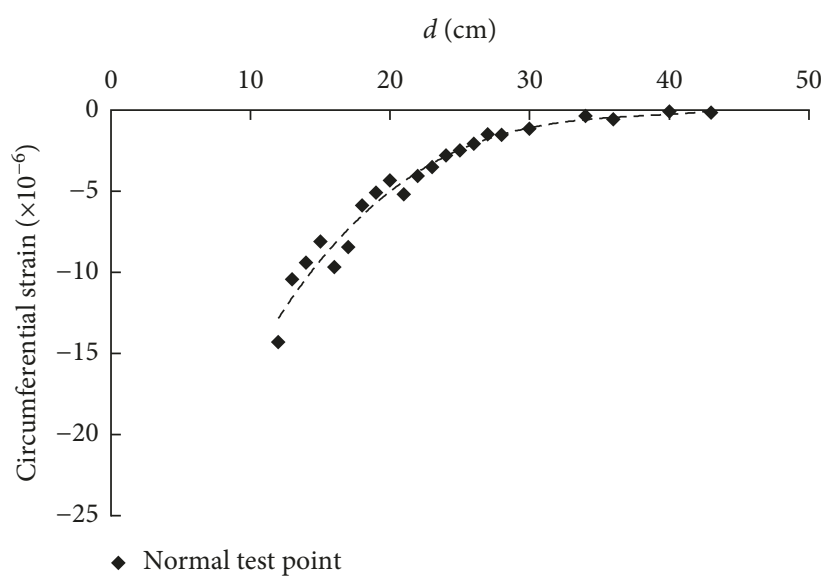

FIGURE 12: Top surface circumferential strain of the CC model after removing the abnormal points.

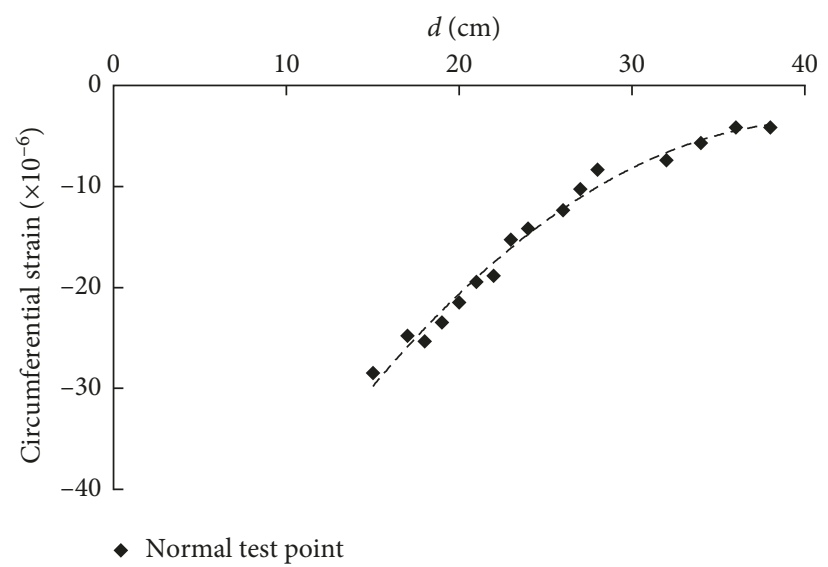

FIGURE 13: Top surface circumferential strain of the AC model after removing the abnormal points.

respectively, which are lower than $5 \%$ and belong to low variation level. The variation coefficients of the CC pavement structure model are $1.9 \%$ and $2.2 \%$, and the variation 
TABLe 5: Parallel test results of circumferential strain of the AC pavement structure model.

\begin{tabular}{|c|c|c|c|c|c|c|}
\hline \multirow{2}{*}{$d(\mathrm{~cm})$} & \multicolumn{5}{|c|}{ Circumferential strain $\left(\times 10^{-6}\right)$} & \multirow{2}{*}{ Variation coefficient } \\
\hline & Model \#1 & Model \#2 & Model \#3 & Model \#4 & Average & \\
\hline 15.0 & -28.5 & -29.3 & -28.4 & -28.9 & -28.8 & $1.4 \%$ \\
\hline 18.0 & -25.3 & -26.2 & -24.8 & -25.8 & -25.5 & $0.4 \%$ \\
\hline 21.0 & -19.5 & -18.9 & -20.2 & -19.9 & -19.6 & $2.3 \%$ \\
\hline 24.0 & -14.2 & -14.8 & -13.9 & -14.6 & -14.4 & $2.7 \%$ \\
\hline 27.0 & -10.3 & -10.5 & -9.9 & -10.5 & -10.3 & $2.1 \%$ \\
\hline 28.0 & -8.4 & -8.3 & -8.4 & -8.5 & -8.4 & $3.0 \%$ \\
\hline 32.0 & -7.4 & -7.6 & -7.3 & -7.6 & -7.5 & $1.9 \%$ \\
\hline 34.0 & -5.7 & -5.7 & -5.9 & -5.8 & -5.8 & $2.0 \%$ \\
\hline 38.0 & -4.2 & -4.2 & -4.0 & -4.2 & -4.1 & $2.7 \%$ \\
\hline Average & & & & & & $2.1 \%$ \\
\hline
\end{tabular}

TABLE 6: Parallel test results of radial strain of the AC pavement structure model.

\begin{tabular}{|c|c|c|c|c|c|c|}
\hline \multirow{2}{*}{$d(\mathrm{~cm})$} & \multicolumn{5}{|c|}{ Radial strain $\left(\times 10^{-6}\right)$} & \multirow{2}{*}{ Variation coefficient } \\
\hline & Model \#1 & Model \#2 & Model \#3 & Model \#4 & Average & \\
\hline 15.3 & -9.7 & -9.4 & -9.7 & -9.8 & -9.6 & $1.8 \%$ \\
\hline 19.0 & -5.4 & -5.6 & -5.2 & -5.5 & -5.5 & $3.2 \%$ \\
\hline 21.5 & 2.5 & 2.5 & 2.5 & 2.6 & 2.5 & $1.2 \%$ \\
\hline 24.0 & 5.9 & 5.7 & 6.1 & 6.0 & 5.9 & $3.4 \%$ \\
\hline 27.8 & 9.8 & 9.6 & 9.9 & 10.1 & 9.8 & $2.2 \%$ \\
\hline 30.3 & 11.3 & 11.8 & 10.8 & 11.7 & 11.4 & $4.0 \%$ \\
\hline 34.0 & 12.8 & 12.9 & 12.6 & 13.3 & 12.9 & $2.3 \%$ \\
\hline 36.5 & 7.6 & 7.7 & 7.6 & 7.8 & 7.7 & $0.9 \%$ \\
\hline 39.0 & 6.7 & 6.9 & 6.5 & 6.9 & 6.8 & $3.0 \%$ \\
\hline 41.5 & 7.0 & 7.1 & 6.9 & 7.2 & 7.1 & $1.9 \%$ \\
\hline 44.0 & 4.7 & 4.5 & 4.7 & 4.7 & 4.7 & $1.9 \%$ \\
\hline Average & & & & & & $2.3 \%$ \\
\hline
\end{tabular}

TABLE 7: Replicate test results of circumferential strain of the AC pavement structure model.

\begin{tabular}{|c|c|c|c|c|c|}
\hline \multirow{2}{*}{$d(\mathrm{~cm})$} & \multicolumn{4}{|c|}{ Circumferential strain $\left(\times 10^{-6}\right)$} & \multirow{2}{*}{ Variation coefficient } \\
\hline & Model \#1 & Model \#2 & Model \#3 & Average & \\
\hline 15.0 & -28.5 & -28.9 & -27.9 & -28.4 & $1.7 \%$ \\
\hline 18.0 & -25.3 & -27.3 & -24.8 & -25.8 & $1.8 \%$ \\
\hline 21.0 & -19.5 & -18.2 & -20.0 & -19.2 & $5.1 \%$ \\
\hline 24.0 & -14.2 & -15.2 & -13.5 & -14.3 & $3.1 \%$ \\
\hline 27.0 & -10.3 & -10.4 & -9.7 & -10.1 & $3.0 \%$ \\
\hline 28.0 & -8.4 & -8.0 & -8.5 & -8.3 & $4.8 \%$ \\
\hline 32.0 & -7.4 & -7.8 & -7.1 & -7.4 & $1.1 \%$ \\
\hline 34.0 & -5.7 & -5.4 & -5.7 & -5.6 & $3.6 \%$ \\
\hline 38.0 & -4.2 & -4.4 & -4.1 & -4.2 & $5.8 \%$ \\
\hline Average & & & & & $3.3 \%$ \\
\hline
\end{tabular}

coefficients of the CSM pavement structure model are $2.1 \%$ and $2.2 \%$, which also belong to low variation level. However, to ensure the accuracy of test results, more than 3 sets of parallel tests are carried out each time for the test. The average value of parallel test results is used as measured strain for compared analyses.
4.2.2. Replicate Test Result. The replicate tests were developed on the AC pavement structure model by three researchers individually under the load intensity of $p=0.7 \mathrm{MPa}$ and the temperature of $25^{\circ} \mathrm{C}$ on different dates which were 7 December 2013 (first time), 21 February 2014 (second time), and 1 March 2014 (third time). The test results 
TABLE 8: Replicate test results of radial strain of the AC pavement structure model.

\begin{tabular}{|c|c|c|c|c|c|}
\hline \multirow{2}{*}{$d(\mathrm{~cm})$} & \multicolumn{4}{|c|}{ Radial strain $\left(\times 10^{-6}\right)$} & \multirow{2}{*}{ Variation coefficient } \\
\hline & Model \#1 & Model \#2 & Model \#3 & Average & \\
\hline 15.3 & -9.7 & -9.5 & -9.8 & -9.6 & $1.8 \%$ \\
\hline 19.0 & -5.4 & -5.8 & -5.4 & -5.5 & $4.2 \%$ \\
\hline 21.5 & 2.5 & 2.6 & 2.5 & 2.5 & $2.6 \%$ \\
\hline 24.0 & 5.9 & 5.9 & 6.2 & 6.0 & $3.1 \%$ \\
\hline 27.8 & 9.8 & 9.2 & 9.8 & 9.6 & $3.7 \%$ \\
\hline 30.3 & 11.3 & 12.1 & 10.6 & 11.3 & $6.4 \%$ \\
\hline 34.0 & 12.8 & 13.7 & 12.5 & 13.0 & $4.6 \%$ \\
\hline 36.5 & 7.6 & 7.9 & 7.4 & 7.7 & $3.5 \%$ \\
\hline 39.0 & 6.7 & 6.8 & 6.4 & 6.7 & $3.0 \%$ \\
\hline 41.5 & 7.0 & 7.2 & 6.6 & 6.9 & $4.5 \%$ \\
\hline 44.0 & 4.7 & 4.8 & 4.4 & 4.6 & $4.5 \%$ \\
\hline Average & & & & & $3.8 \%$ \\
\hline
\end{tabular}

are listed in Tables 7 and 8, which indicate that the differences between the results of the 3 sets of replicate tests are very small. The average variation coefficients of circumferential strain and radial strain are 3.3\% and 3.8\%, respectively, which belong to low variation level. At the same time, the replicate tests were conducted on CC and CSM pavement structure models. The average variation coefficients of circumferential strain and radial strain are $3.9 \%$ and $3.1 \%$ for the CC pavement structure model and 3.2\% and $4.0 \%$ for the CSM pavement structure model, which also belong to low variation level. All these results indicate that this test method has high repeatability. Thus, the test methods can be used as an effective way to study the mechanical response of pavement structure.

\subsection{Discussions}

\subsubsection{Influence of Pavement Materials on Strain}

\section{(i) Test results}

The test results of circumferential strain of the pavement structure models with three pavement materials are presented in Figure 14. It can be seen that, under the same test conditions, the trends of circumferential strain of the CC, $\mathrm{CSM}$, and AC pavement structure model changing with the distance $d$ from the test point to the center point of load are similar. The circumferential strain of the models with three kinds of materials is all compressive strain, which decreases as the distance from the test point to the center point of load increases. The strain data decrease to 0 at the edge of the model.

The strain at the same test point is in inverse proportion to the modulus of the pavement material. In the order of highest value of the circumferential strain, the sequence is AC, CSM, and CC.

The test results of radial strain of CC, CSM, and AC structure models under the stress level (the ratio of stress to strength) of 0.3 and temperature of $15^{\circ} \mathrm{C}$ are shown in Figure 15. It reveals that, under the same stress level and test

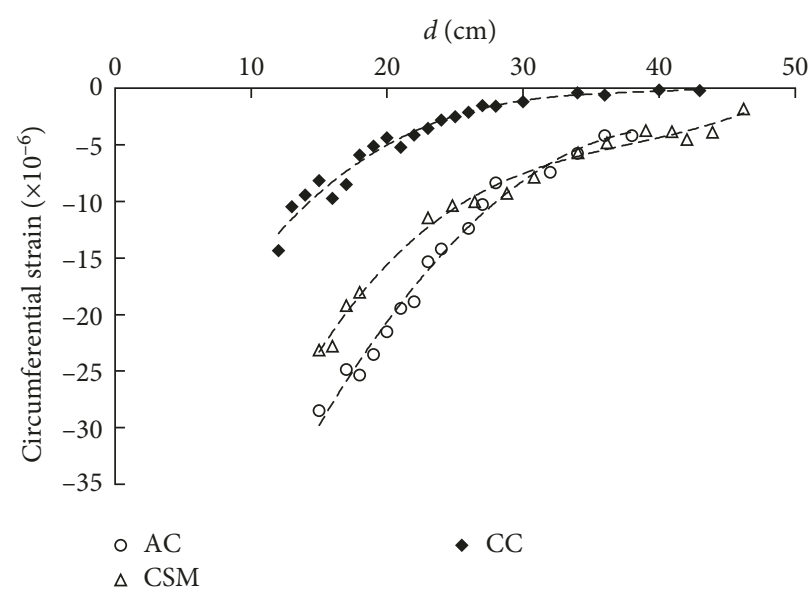

Figure 14: Circumferential strain test results of models with different pavement materials.

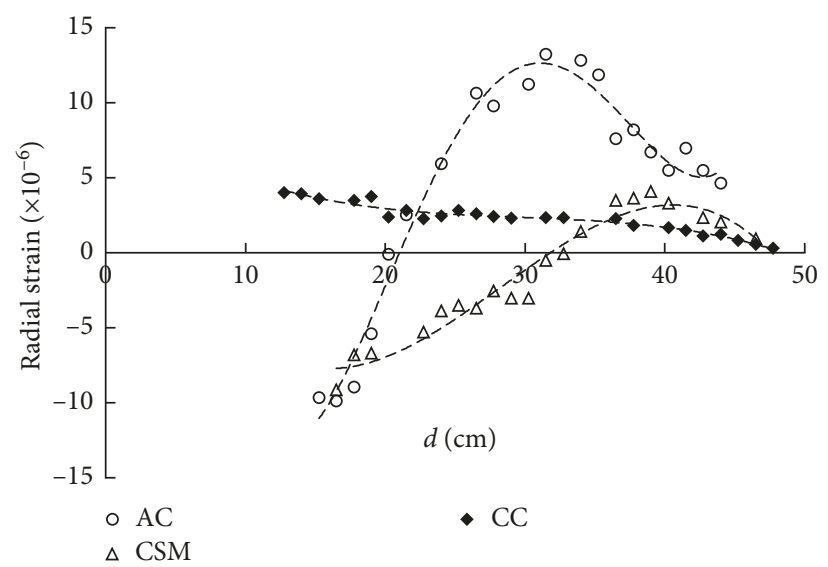

FIgURE 15: Radial strain test results of models with different pavement materials.

temperature, the trends of radial strain of the three kinds of pavement structure models are quite different. Radial strain of the CC structure model is tensile strain, which decreases 
TABLE 9: Calculation parameters of BISAR.

\begin{tabular}{lccccc}
\hline Type of material & Stress level & Load, $p(\mathrm{MPa})$ & Radius of the load circle, $\delta(\mathrm{cm})$ & Structural layer modulus, $E(\mathrm{MPa})$ & Poisson's ratio, $\mu$ \\
\hline CC & 0.3 & 2.1 & 7.5 & 25,000 & 0.17 \\
CSM & 0.3 & 1.5 & 7.5 & 3600 & 0.30 \\
AC & 0.3 & 0.7 & 7.5 & 1200 & 0.30 \\
\hline
\end{tabular}

as the distance $d$ between the test point and the load central point increases and further decreases to 0 nearby the model boundary, whereas radial strain of CSM and AC structure models shows an alternation from compression to tensile strain. Radial strain nearby the load is the biggest. As the distance $d$ from the test point to the load central point increases, the compression strain decreases to 0 and converts into the tensile strain. After reaching a peak value, the tensile strain decreases gradually and finally decreases to 0 nearby the boundary of the model. There are maximum compressive strain point, compressive-tensile cutoff point, and tensile strain peak point for the radial strain of CSM and AC structure models obviously. These points can reflect the mechanical response characteristics of the pavement structure model under the load action. Accordingly, these points are defined as the mechanical response feature points. The strain values at the feature points are defined as the feature values of mechanical response. Due to the influences of pavement material properties, the feature points and feature values of the radial strain of CSM and AC structure models are different. The compressive-tensile cutting point of CSM and AC pavement structure models lie in the position of $d=32 \mathrm{~cm}$ and $d=21 \mathrm{~cm}$ off the load central point. The peak value of tensile strain is $4.1 \mu \varepsilon$ and $13.2 \mu \varepsilon$, which appear in the position of $d=39 \mathrm{~cm}$ and $d=32 \mathrm{~cm}$ off the load central point, respectively. For the AC pavement, there are obvious compressive zone and tensile zone. Compared with CSM pavement, the tensile zone of AC pavement is wider and the peak value of tensile strain is higher. Thus, heavy load leads to large tensile strain, which may result in the topdown crack on the surface of AC pavement.

In conclusion, under the same test conditions, the mechanical response of CC, CSM, and AC are different with each other distinctly.

(ii) Comparison between test results and theoretical calculations

In order to study the deviation between real mechanical response and theoretical calculations, software for mechanical analysis based on the elastic layered system, BISAR3.0, was employed for theoretical calculations of the strain on the top surface of CC, CSM, and AC pavement models. The calculation parameters of BISAR are displayed in Table 9.

The test results and theoretical calculations of the circumferential strain and radial strain of CC, CSM, and AC pavement structure models are shown in Figure 16. It indicates that the theoretical calculations of circumferential strain present a coincident trend with the test results. The circumferential strain decreases with the increase of the distance $d$ from the test point to the load central point. The theoretical calculation values and test results of radial strain of the CC pavement structure model also display a good match with each other, whereas the theoretical calculation results of the CSM and AC pavement structure models reveal the total different regulations with the test results. The radial strain of theoretical calculation of CSM and AC pavement structure models is tensile strain, which decreases with the increase in the distance $d$ off the load central point. However, the test results of the radial strain of CSM and AC pavement structure models include the compressive zone and tensile zone with an obvious compressive-tensile cutting point. There is no correlation between theoretical calculation values and test results. As listed in Table 9, the theoretical calculation models of three pavement structure are distinguished only by changing the modulus and Poisson's ratio of the pavement materials without considering the influence of constitutive relations on the mechanical response of the model, which may be the reason resulting in the different trends of theoretical calculation values with the test results. Comparison results between the theoretical calculation values and test results indicate that the elastic layered system is suitable for the CC pavement, whereas appropriate modification is needed on the elastic layered system for the CSM and AC pavement.

In conclusion, because of the different material properties, the mechanical response is different obviously under the same conditions. Hence, the material property should be fully considered in the theoretical calculation model in order to obtain the more accurate calculation values to reflect the mechanical response of actual pavement structure.

4.3.2. Influence of Load Level on Test Results. The test results of circumferential strain and radial strain of the CC pavement structure model under the different load levels of $p=1.3 \mathrm{MPa}, 1.7 \mathrm{MPa}$, and 2.1 $\mathrm{MPa}$ are displayed in Figure 17. It reveals that all the circumferential strains are compressive and all the radial strains are tensile. For the same distance $d$ off the load central point, the strain value of the CC model increases with the increasing load level. Under the different load levels, the strain displays the same trend which decreases with the increasing distance $d$ off the load central point and becomes 0 at the boundary of the model. Especially for the circumferential strain, when distance $d$ ranges from $10 \mathrm{~cm}$ to $35 \mathrm{~cm}$, the strain at same test point increases with the increase of the load level. When distance $d>35 \mathrm{~cm}$, there is little difference among the circumferential strains under three load levels.

The test results of circumferential strain and radial strain for the CSM model under different load levels of $p=1.1 \mathrm{MPa}$, 1.5 $\mathrm{MPa}$, and 1.9 $\mathrm{MPa}$ are displayed in Figure 18. It can be seen that the strain of the CSM model increases with the 


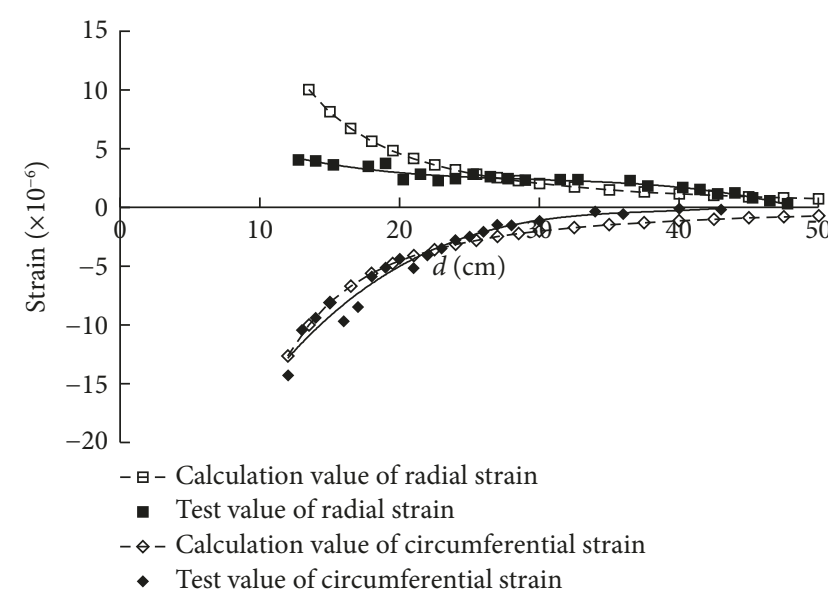

(a)

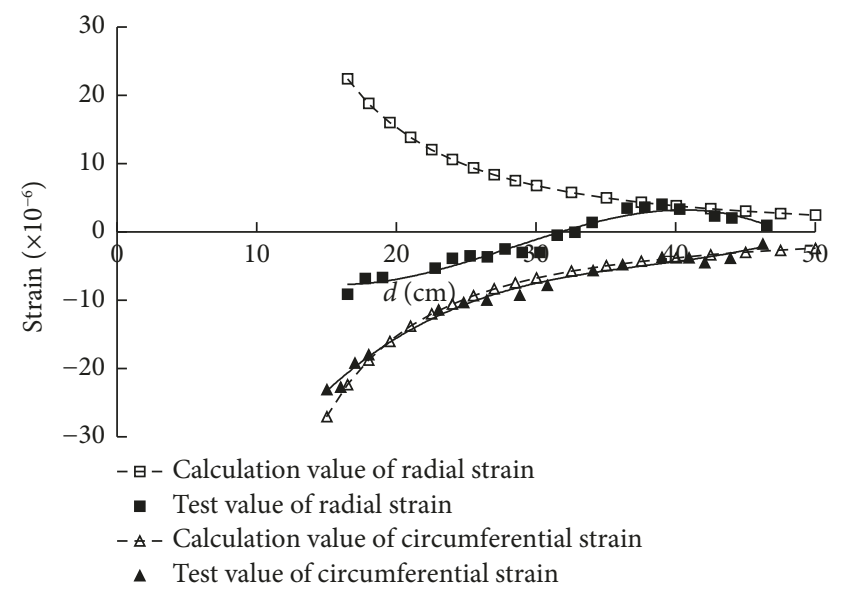

(b)

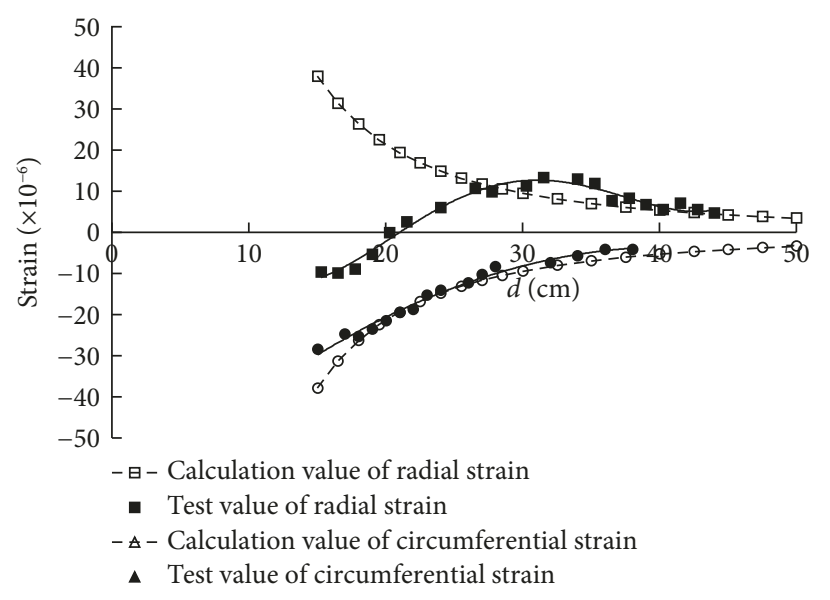

(c)

FIGURE 16: Test results and calculation values of strain. (a) CC. (b) CSM. (c) AC.

increasing load level. Under the different load levels, the strain shows the same trend. When distance $d$ ranges from $10 \mathrm{~cm}$ to $30 \mathrm{~cm}$, there are obvious differences among circumferential strains under the different load levels at the same test point. However, when $d>30 \mathrm{~cm}$, the differences become tiny and approach to 0 at the boundary of the model.

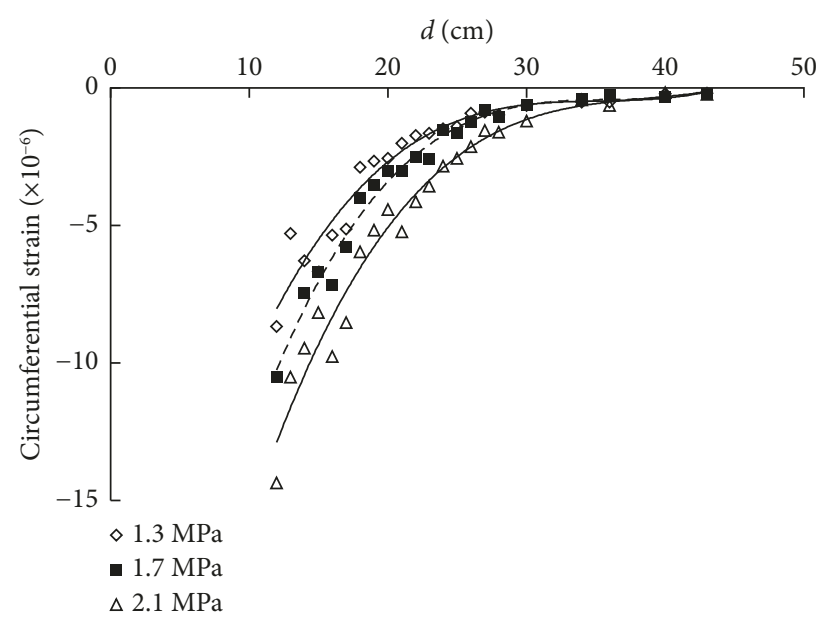

(a)

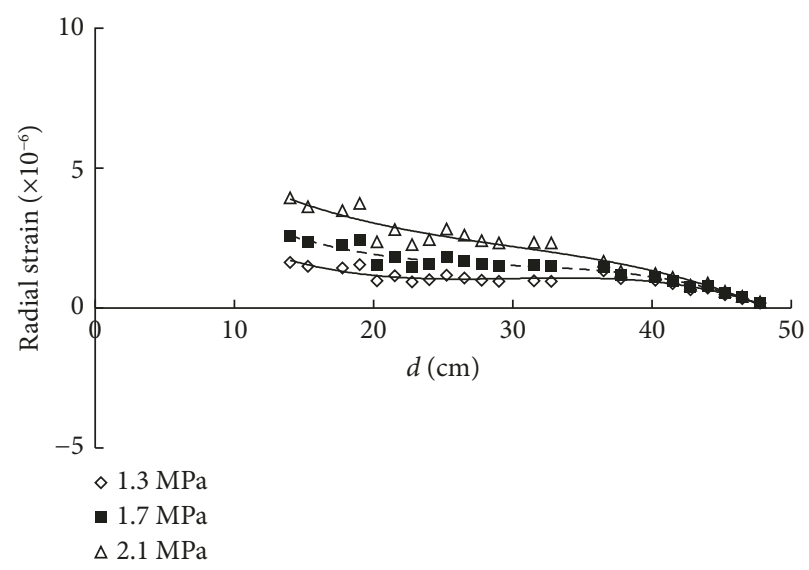

(b)

FIGURE 17: Strain test results of the CC pavement structure model under the different load levels. (a) Circumferential strain. (b) Radial strain.

There are mechanical response feature points for the radial strain of the CMS pavement structure model under the different load levels. The positions of the feature points are the same for the different load levels that the compressivetensile cutoff points appear at $d=32 \mathrm{~cm}$ and peak points of tension strain appears at $d=39 \mathrm{~cm}$. However, the maximum compressive strain and the peak tension strain increase with the increasing load level.

The test results of circumferential strain and radial strain for the AC pavement model under different load levels of $p=0.3 \mathrm{MPa}, 0.7 \mathrm{MPa}$, and $1.1 \mathrm{MPa}$ are shown in Figure 19 . As displayed, the strain of the AC pavement structure model increases with the raise of load level and shows basically the same trend under the different load levels. For the circumferential strain of the AC pavement model, the greater the load level, the steeper the curve and vice versa. Similar to the CSM model, mechanical response feature points remain in original position without any change when the load level increases so that the compression-tension cutoff points appear at $d=21 \mathrm{~cm}$ and peak points of tensile strain appears at $d=32 \mathrm{~cm}$. Similar to the CSM model, 


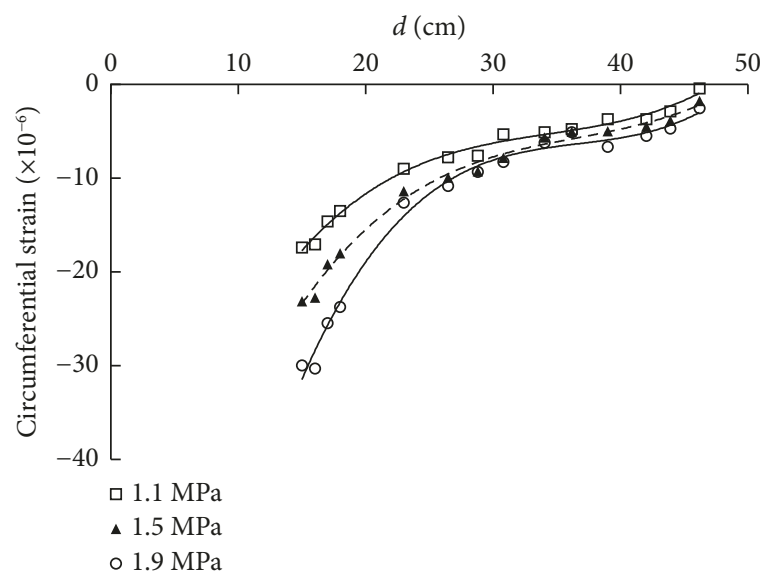

(a)

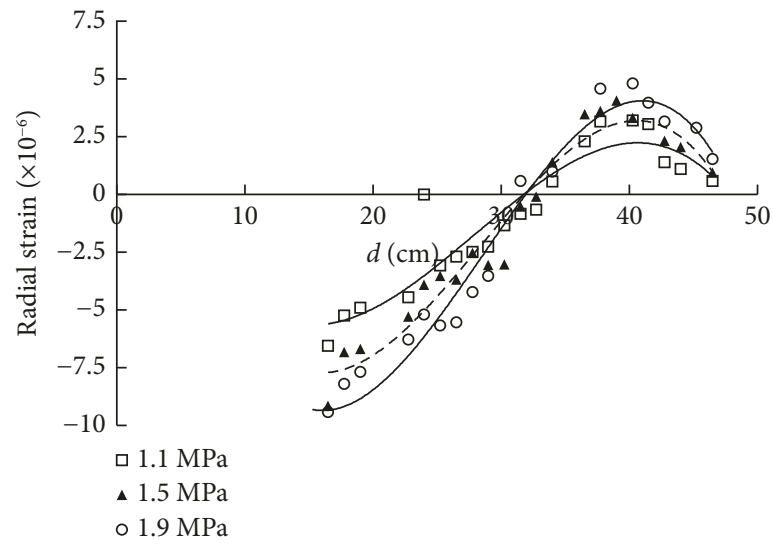

(b)

Figure 18: Strain test results of the CSM pavement structure model under the different load levels. (a) Circumferential strain. (b) Radial strain.

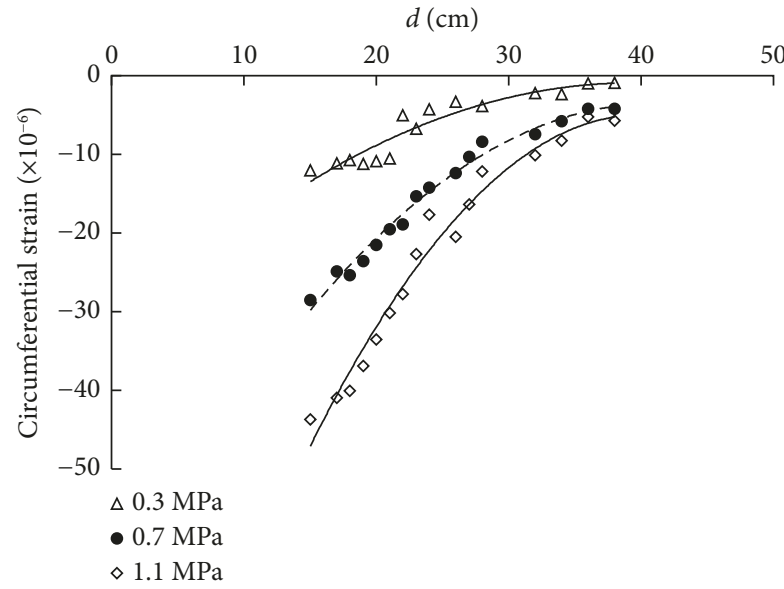

(a)

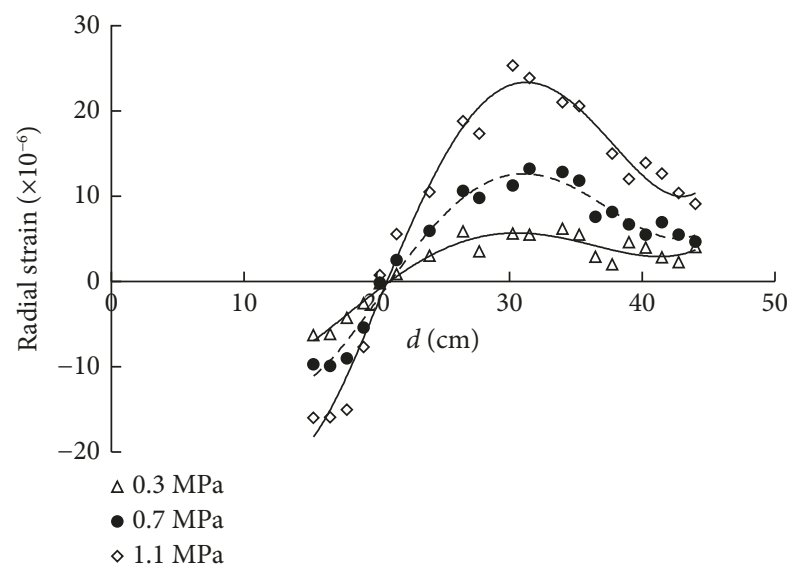

(b)

FIGURE 19: Strain test results of the AC pavement structure model under the different load levels. (a) Circumferential strain. (b) Radial strain.

the maximum compressive strain and peak tensile strain increase with the increasing load level.

\section{Conclusions}

Based on the results from this study, the following conclusions can be drawn.

A test method for mechanical response of pavement structure with a large-scale model was presented in the research, which proves to be a reliable method to study the mechanical response of pavement structure while the fullscale accelerated loading test is not available. The research results can provide some references for theoretical calculation of pavement structure and determination of pavement material parameters.

The mechanical responses of three typical pavement materials, CSM, AC, and CC, were studied by large-scale test, which show great differences with each other under the same test conditions. There are obvious mechanical response feature points for radial strain of CSM and AC, which are maximum compression strain point, compressive-tensile cutoff point, and tensile strain peak point, while the phenomenon does not exist on the CC pavement structure, which suffers tensile radial strain on all the test points.

There is a large difference between the test results and theoretical calculation values of radial strain for both CSM and AC pavement structures, which indicates that the elastic layered system need to be modified for theoretical calculation of mechanical response of CSM and AC pavement structures.

All the strains of CC, CSM, and AC pavement structures increase as the load level increases. However, for each pavement structure, under the different load levels, the trends of strain changing with the distance from the test point to the load central point are similar. The mechanical response feature points of CSM and AC pavement structures stay at the same position under the different load levels, but the feature values change. 
For the AC pavement structure, there are obvious compressive zone and tensile zone. The top-down cracks may appear on the surface due to the maximum tensile strain beyond the tensile strength when heavy load is applied.

\section{Further Research}

This is a preliminary test method for mechanical response of pavement structure with the large-scale model, in which the pavement structure is simplified to a single layer. The largescale model with multilayers which is more similar to the real pavement structure should be prepared in the further researches. Furthermore, the test results of the mechanical responses of the large-scale model will be compared with the results of the full-scale test to verify the accuracy of the test method with the large-scale model.

\section{Conflicts of Interest}

The authors declare that they have no conflicts of interest.

\section{Acknowledgments}

The authors would like to thank the Key Laboratory of Road Structure and Material, Research Institute of Highway Ministry of Transport, Beijing, China, and the Fundamental Research Funds for the Central Public Research Institutes (2015-9027) for supporting this research project.

\section{References}

[1] C. Xiao, Y. J. Qiu, and B. Huang, "Analysis on dynamic response of asphalt pavement based on vehicle loading test," Journal of Highway and Transportation Research and Development, vol. 31, no. 12, pp. 12-19, 2014.

[2] P. Kadar and J. Mclean, "Experience with the Australian Accelerated Loading Facility," in Proceedings of the International Conference on Bearing Capacity of Roads and Airfields, Plymouth, United Kingdom, 1986.

[3] K. G. Sharp, "The efficiency and effectiveness of the Australian Accelerated Loading Facility (ALF) program," Road \& Transport Research, vol. 1, no. 2, pp. 104-107, 1992.

[4] L. D. Plessis, F. Jooste, S. Keckwick, and W. Steyn, HVS Testing of the Palmdale Test Site, North Tangent Sections: Evaluation of Long Life Pavement Rehabilitation Strategies-Rigid, Institute of Transportation Studies, Working Paper, Berkeley, CA, USA, 2005.

[5] F. Rust, S. V. Kekwick, E. G. Kleyn, and E. S. Sadzik, "The impact of the heavy vehicle simulator (HVS) test programme on road pavement technology and management," in Proceedings of the Eighth International Conference on Asphalt Pavements, Seattle, Washington, USA, August 1997.

[6] M. D. Beer, E. M. Sadzik, C. Fisher, and C. H. Coetzee, "Tyrepavement contact stress patterns from the test tyres of the Gautrans heavy vehicle simulator (HVS) MK IV+," in Proceedings of the 24th Southern African Transportation Conference (SATC), Pretoria, South Africa, July 2005.

[7] M. Huhtala, "The effect of different trucks on road pavements," in Proceedings of the International Symposium on Heavy Vehicle Weights and Dimensions, Kelowna, BC, Canada, June 1986.
[8] D. H. Timm, A. L. Priest, and T. V. McEwen, Design and Instrumentation of the Structural Pavement Experiment at the NCAT Test Track, NCAT Report, National Center for Asphalt Technology, Auburn, AL, USA, 2004.

[9] A. L. Priest and D. H. Timm, "A full-scale pavement structural study for mechanistic-empirical pavement design," Journal of the Association of Asphalt Paving Technologists, vol. 74, pp. 110-114, 2005.

[10] B. W. Tsai, J. T. Harvey, and C. L. Monismith, "WesTrack fatigue performance prediction using Miner's law," Transportation Research Record, vol. 1809, pp. 137-147, 2002.

[11] M. I. Nguyen, J. M. Balay, C. Sauzeat et al., "Accelerated pavement testing experiment of a pavement made of fiberreinforced roller-compacted concrete," in Proceedings of the International Conference on Accelerated Pavement Testing, Davis, California, USA, 2012.

[12] M. L. Hines, L. R. C. De, and P. Chaverot, "Evaluation of fatigue behavior of hot mix asphalt with the LCPC nantes test track and SHRP testing tools," Journal of the Association of Asphalt Paving Technologists, vol. 67, pp. 717-737, 1998.

[13] J. Corte, Y. Brosseaud, J. Kerzreho, and A. Spernol, "Study of rutting of wearing courses on the LCPC test track," in Proceddings of the Eighth International Conference on Asphalt Pavements, Seattle, Washington, USA, 1997.

[14] M. T. Do, J. P. Kerzreho, J. M. Balay, and M. Gothie, "Full scale tests for the assessment of wear of pavement surfaces," in Proceedings of the Transportation Research Board (TRB) Annual Meeting, Washington DC, USA, 2003.

[15] B. M. Villalobos, J. P. Ayuso, J. A. Campos, J. B. Perze, and J. T. Rodriguez, "Installation and analysis of sensors used in the full scale test track of the road studies centre (CEDEX)," in Proceedings of the 16th International Symposium on Automation and Robotics in Construction (ISARC), Madrid, Spain, 1999.

[16] J. P. Ayuso, B. C. Jauregui, and A. Mateos, "Managing data from instrumentation in the CEDEX test track," in Proceedings of the 26th International Symposium on Automation and Robotics in Construction (ISARC), Austin, Texas, USA, June 2009.

[17] F. Hugo, Texas Mobile Load Simulator Test Plan, Texas Department of Transportation, University of Texas at Austin, Austin, TX, USA, 1996.

[18] X. D. Wang, "Design of pavement structure and material for full-scale test track," Journal of Highway and Transportation Research and Development, vol. 34, no. 6, pp. 30-37, 2017.

[19] X. Y. Zhou, X. D. Wang, and B. Su, "Study on mechanical response test method for real pavement structure model," Journal of Highway and Transportation Research and Development, vol. 34, no. 6, pp. 23-29, 2017.

[20] F. Zeng and X. D. Wang, "Design and construction of long-life semi-rigid pavement: investigation from test sections in northern and southern China," in Proceedings of the Transportation Research Board (TRB) 2016 Annual Meeting, Washington DC, USA, 2016.

[21] Highway Research Board, The AASHO Road Test History and Description of Project, National Academy of Sciences-National Research Council, Washington, DC, USA, 1961.

[22] H. B. Baker, M. R. Buth, and D. A. Van Deusen, Minnesota Road Research Project: Load Response Instrumentation Installation and Testing Procedures, Report No. MN/PR-94/01[R], pp. 1-34, Minnesota Department of Transportation, Maplewood, MN, USA, 1994.

[23] J. C. Wei, L. Wang, Y. S. Yang et al., "Numerical simulation of mechanical response of perpetual road test asphalt 
pavement," Journal of Highway and Transportation Research and Development, vol. 27, no. 6, pp. 15-19, 2010.

[24] Z. J. Dong, H. Liu, Y. Q. Tan et al., "Field measurement of three-direction strain response of asphalt pavement," Journal of South China University of Technology: Natural Science Edition, vol. 37, no. 7, pp. 46-51, 2009.

[25] D. Z. Guo and D. C. Feng, Layered Elastic System Mechanics, Harbin Institute of Technology Press, Harbin, China, 2001.

[26] M. Li, X. D. Wang, and N. M. Zhang, "Finite deformation analysis of layered asphalt pavement," Journal of Applied Sciences, vol. 13, no. 12, pp. 2146-2150, 2013.

[27] S. Bhattacharjee and R. B. Mallick, "Determination of damage development in asphalt concrete using small-scale accelerated pavement testing via frequency domain analysis approach," Journal of Transportation Engineering, vol. 138, no. 6, pp. 723-731, 2012.

[28] Z. K. Yao, Structural Design of Asphalt Pavements, China Communications Press, Beijing, China, 2011. 


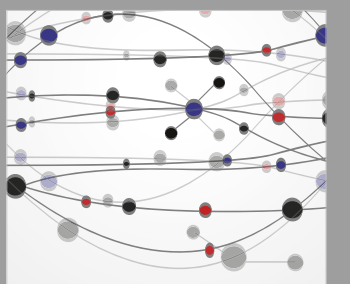

The Scientific World Journal
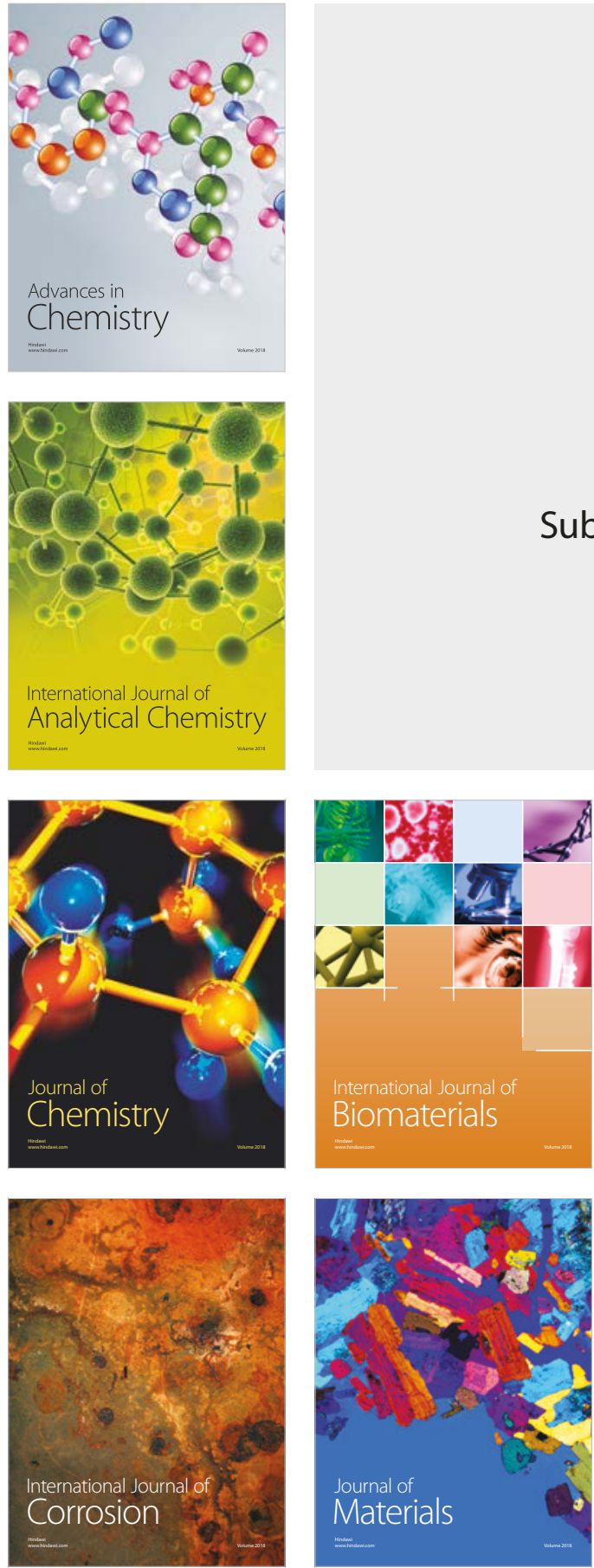

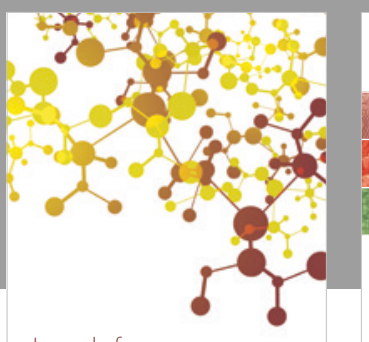

Journal of

Applied Chemistry
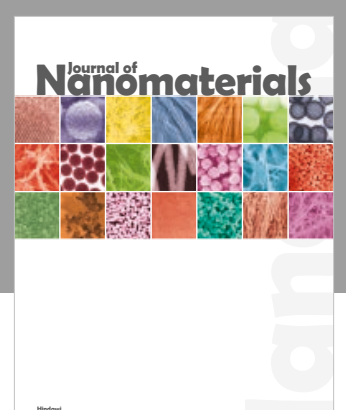

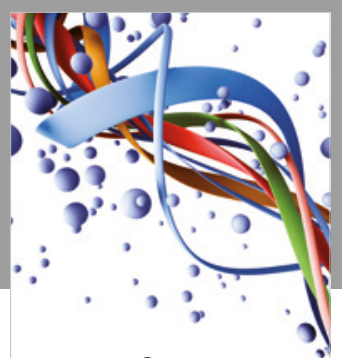

Scientifica

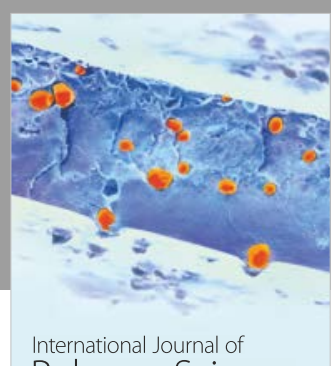

Polymer Science

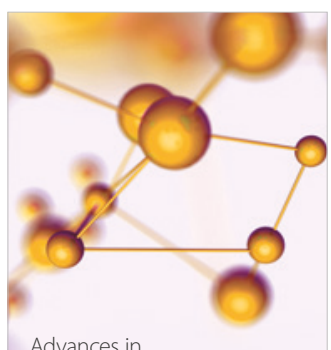

Physical Chemistry
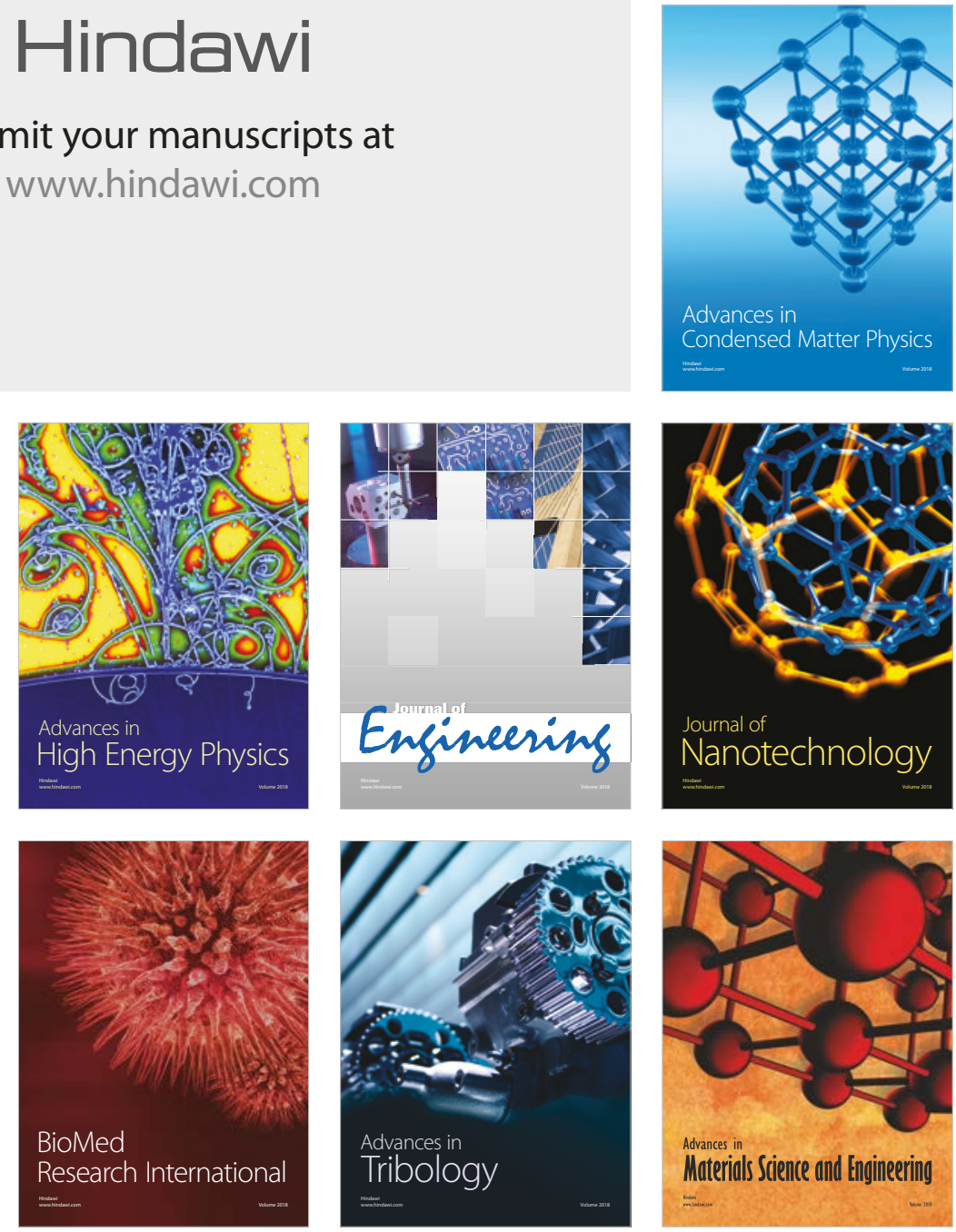